\title{
Effect of Marine Bacillus BC-2 on the Health-Beneficial Ingredients of Flavor Liquor
}

\author{
Yueming $\mathrm{Li}^{*}$, Jianchun $\mathrm{Xu}$, Zhimei Xu \\ Qingdao Langyatai Group Co., Ltd., Qingdao, China \\ Email: *xjclyt@126.com
}

How to cite this paper: Li, Y.M., Xu, J.C. and Xu, Z.M. (2019) Effect of Marine Bacillus BC-2 on the Health-Beneficial Ingredients of Flavor Liquor. Food and Nutrition Sciences, 10, 606-612.

https://doi.org/10.4236/fns.2019.106044

Received: March 27, 2019

Accepted: June 11, 2019

Published: June 14, 2019

Copyright $\odot 2019$ by author(s) and Scientific Research Publishing Inc. This work is licensed under the Creative Commons Attribution International License (CC BY 4.0).

http://creativecommons.org/licenses/by/4.0/

\begin{abstract}
The main aroma component of Luzhou-flavor Liquor is ethyl caproate, which is combined with appropriate amount of ethyl butyrate, ethyl acetate, ethyl lactate and so on. By adding the marine bacillus BC-2 (Accession number: MK811408) to substrate sludge, the bacillus complex bacterial liquid (pit Mud Functional Bacterial liquid) has been modified. The complex bacterial liquid was used in the production of Luzhou-flavor Liquor and it dramatically promoted the content of health-beneficial ingredients in the new workshop. These results demonstrated that the marine bacillus BC-2 can effectively improve the quality and health benefit of Luzhou-flavor Liquor.
\end{abstract}

\section{Keywords}

Luzhou-Flavor Liquor, Marine Bacillus BC-2, Flavoring Components

\section{Introduction}

In China, Luzhou-flavor Liquor is the most widely used Luzhou-flavor Liquor in social intercourse and its taste is closely related to the quality of pit mud. Pit mud is the place where bacillus grows, propagates and metabolizes to produce function factors, whose content affects the quality and health benefit of Luzhou-flavor Liquor [1].

Trace element composition is a scientific index for evaluating Luzhou-flavor Liquor quality. Previous studies have shown that Luzhou-flavor Liquor quality and aroma are attracting more and more attention [2]. Ethanol and water are the main components of Luzhou-flavor Liquor; they account for 98\% - 99.9\% (e.g. vodka) of the total Luzhou-flavor Liquor [3], while the remaining $2 \%$ is essential, such as alcohols, organic acids, esters, phenols and so on [4]. These microelements have a great influence on the quality of Luzhou-flavor Liquor and determine the different aroma and flavor characteristics of different liquors. Thus 
there are different flavor styles of liquor. According to the fragrance types, the common are: fragrance, sauce, strong fragrance, sesame and rice fragrance, etc. Moreover, low molecular organic acids, lactones, phenols and heterocycles are the beneficial ingredients included in liquor [5]. Among them, tetramethylpyrazine, 4-methyl guaiacol and 4-ethyl guaiacol are aromatic and odorous substances commonly contained in liquor and they have certain physiological activities. Especially, tetramethylpyrazine, which contributes sweetness, fruit and flower fragrance to wine, has physiological effects such as inhibiting platelet aggregation, improving microcirculation and reducing brain atrophy injury [6] and the phenolic compounds, 4-methyl guaiacol and 4-ethyl guaiacol are excellent free radical eliminators, which have good antioxidant, anti-tumor and enhancing human immunity [7] [8] [9]. Therefore, the study of these three beneficial components in liquor has certain guiding significance for exploring the health benefits of liquor.

In the actual production process, the degradation of pit mud will lead to the decrease of ethyl caproate content in Luzhou-flavor Liquor, which seriously affects the flavor and taste of liquor [1]. At present, researchers have adopted many methods to repair the aged pit mud, such as super-concentrated compound bacillus solution [10], solid (liquid) pit mud functional bacteria [10], artificial pit mud resistance [11] and so on, to remedy the adverse consequences of pit mud degradation.

In this study, we added marine bacillus BC-2 to pit mud and then modify the bacillus complex bacterial liquid. The modified complex was used to cultivate artificial old pit mud and to produce Luzhou-flavor Liquor. The content of 4-methyl guaiacol in liquor in which new pit mud functional bacterial liquid was greatly increased from $305.17 \mathrm{~g} / \mathrm{L}$ to $567.47 \mathrm{~g} / \mathrm{L}$. Furthermore, the content of 2,3,4,5,6-Tetramethylpyrazine also increased dramatically from $974 \mathrm{~g} / \mathrm{L}$ to 1400 $\mathrm{g} / \mathrm{L}$. These results showed that the marine bacillus BC-2 can be used to improve the health factor of Luzhou-flavor Liquor.

\section{Material and Methods}

\subsection{Materials and Reagents}

Bacillus: screened from Mariana trench seawater.

Seed liquid preparation: Beef extract $5 \mathrm{~g}$, peptone $10 \mathrm{~g}$, sodium chloride $5 \mathrm{~g}$, water $1000 \mathrm{~mL}, \mathrm{pH}=7.0-7.2$. The prepared seed culture liquid was separated into triangular bottles, sealed with a sealed film, wrapped in newspapers, and then sterilized in a high-pressure sterilizing pot. The sterilization conditions were $121^{\circ} \mathrm{C}$ and $20 \mathrm{~min}$. Activated strains were inoculated into triangular flasks containing seed culture medium. The volume of liquid was 100/250 mL, $130 \mathrm{r} / \mathrm{min}$ in oscillator and $24 \mathrm{~h}$ in oscillatory culture at $37^{\circ} \mathrm{C}$.

\subsection{Brewing of Luzhou-Flavor Liquor}

The basic control parameters Luzhou-flavor liquor brewing included grain-steeping 
time, primary steaming and secondary steaming time, moisture content of grains after steaming, starter use level, and grains blending ratio. In order to drive out the odor and harmful substances in rice husk, the rice husk should be steamed for 30 - 40 minutes beforehand and then controlled the pit entry temperature is generally controlled by $15 \%$ to $17 \%$ starch concentration, acidity below 2.0 , moisture $55 \%-58 \%$, temperature at $18^{\circ} \mathrm{C}-20^{\circ} \mathrm{C} .1-1.5 \mathrm{~kg}$ Daqu grains were sprinkle powder on the bottom of cellar to promote aroma generation.

\subsection{Composition Determination}

Take three bottles of Luzhou-flavor Liquor as sample, using the test methods of Light-color-heat-mass-meta-chemistry technology, GCMS Gas Chromatography-Mass Spectrometry, ICP-MS Inductively Coupled Plasma Mass Spectrometer, GC Gas Chromatograph, High Performance Liquid Chromatograph, Automatic Karl Fischer moisture analyzer, and SPME-HSGCMS Solid Phase Microextraction-Headspace Gas Chromatography-Mass Spectrometer.

\section{Results}

The modified the bacillus complex bacterial liquid optimized mixed was used to replace the traditional pit mud and then produce Luzhou-flavor Liquor under existing mature production conditions. The trace elements in Luzhou-flavor Liquor under the existing mature production conditions were determined to analyze the quality of Luzhou-flavor Liquor before and after adding marine bacillus BC-2. Changes of element contents in compound pit Luzhou-flavor Liquor of before and after added ocean bacillus were shown in Table 1 . We can find that the content of element contents in flavor Luzhou-flavor Liquor with and without compound pit mud of marine bacillus BC-2 changed little. This means that the Luzhou-flavor Liquor aroma did not affect by adding of marine bacillus BC-2.

Although the addition of marine bacillus BC-2 did not affect the aroma of Luzhou-flavor Liquor, we also found that the contents of three function factors that determine Luzhou-flavor Liquor function increased to varying degrees. From Table 2, we can easily found that the quality of Luzhou-flavor Liquor produced by optimized marine bacillus BC-2 is obviously better than that produced by conventional sediment. The content of 4-methyl guaiacol in flavor Luzhou-flavor Liquor produced by functional bacteria of compound pit mud increased greatly, reaching from $305.17 \mu \mathrm{g} / \mathrm{L}$ to $567.47 \mu \mathrm{g} / \mathrm{L}$. The 2,3,4,5,6-Tetramethylpyrazine also increased greatly from $974 \mu \mathrm{g} / \mathrm{L}$ to $1400 \mu \mathrm{g} / \mathrm{L}$. The marine bacillus BC-2 can effectively improve the health factors of flavor Luzhou-flavor Liquor.

\section{Discussion}

Previous studies have shown that Luzhou-flavor Liquor quality and aroma are determined by aromatic organic compounds [3]. Results here demonstrated that 
Y. M. Li et al.

Table 1. Changes of element contents in compound pit Luzhou-flavor Liquor of before and after added ocean bacillus.

\begin{tabular}{|c|c|c|c|c|c|}
\hline Element & $\begin{array}{l}\text { Before } \\
(\mu \mathrm{g} / \mathrm{L})\end{array}$ & $\begin{array}{c}\text { After } \\
(\mu \mathrm{g} / \mathrm{L})\end{array}$ & Element & $\begin{array}{l}\text { Before } \\
(\mu \mathrm{g} / \mathrm{L})\end{array}$ & $\begin{array}{c}\text { After } \\
(\mu \mathrm{g} / \mathrm{L})\end{array}$ \\
\hline Ethyl hexanoate & 205.94 & 206.3 & Ethyl laurate & 0.44 & 0.46 \\
\hline Ethyl lactate & 187.4 & 186.3 & Ethyl myristate & 0.33 & 0.37 \\
\hline ethyl acetate & 158.9 & 159.8 & Ethyl palmitate & 8.7 & 8.9 \\
\hline Ethyl butyrate & 24.3 & 24.8 & Ethyl oleate & 2.6 & 2.9 \\
\hline Ethyl valerate & 6.8 & 6.9 & Ethyl linoleate & 3.5 & 3.7 \\
\hline Ethyl palmitate & 5.3 & 5.1 & 2,3-butanediol & 4.2 & 4.1 \\
\hline Ethyl linoleate & 2.1 & 1.9 & Decyl Alcohol & 3.11 & 3.2 \\
\hline Ethyl oleate & 2.4 & 2.6 & Beta phenylene alcohol & 2.9 & 3.1 \\
\hline Ethyl decate & 1.9 & 2.3 & Lauric acid & 1.1 & 1.2 \\
\hline Ethyl heptanate & 2.7 & 2.9 & Myristic acid & 0.55 & 0.51 \\
\hline Ethyl caprylate & 5.6 & 5.7 & Formic acid & 8.1 & 8.2 \\
\hline Ethyl formate & 8.6 & 8.6 & Acetic acid & 51.4 & 51.1 \\
\hline Terbutyl acetate & 4.07 & 4.1 & propionic acid & 1.3 & 1.6 \\
\hline Isoamyl acetate & 0.97 & 1.02 & Butyrate & 14.11 & 14.6 \\
\hline Caproic acid propyl ester & 1.55 & 1.59 & Valerate & 1.8 & 1.9 \\
\hline Isopentyl hexanoate & 1.33 & 1.36 & Caproic acid & 27.3 & 28.5 \\
\hline Ethyl nonyl & 4.2 & 4.3 & Heptanic acid & 0.2 & 0.18 \\
\hline Diethyl butyroacetate & 6.6 & 6.7 & Bitter & 0.2 & 0.21 \\
\hline Ethyl hexanoate & 204.1 & 206.3 & Pelargonic acid & 0.009 & 0.012 \\
\hline Ethyl lactate & 183.3 & 186.3 & Decic acid & 0.033 & 0.039 \\
\hline Ethyl acetate & 159.7 & 159.8 & Palmitic acid & 0.25 & 0.27 \\
\hline Ethyl butyrate & 24.8 & 24.8 & Linoleic acid & 0.46 & 0.42 \\
\hline Ethyl valerate & 6.5 & 6.9 & Isobutyric acid & 1.2 & 1.23 \\
\hline Ethyl palmitate & 5.2 & 5.1 & Isovalerate & 1.5 & 1.42 \\
\hline Ethyl linoleate & 1.8 & 1.9 & Eighteen acid & 0.026 & 0.026 \\
\hline Ethyl oleate & 2.5 & 2.6 & Lauric acid & 0.05 & 0.036 \\
\hline Ethyl decate & 2.1 & 2.3 & Myristic acid & 0.044 & 0.046 \\
\hline Ethyl heptanate & 2.9 & 2.9 & Oxalate & 22.01 & 22.03 \\
\hline Ethyl caprylate & 5.6 & 5.7 & Tartaric acid & 0.089 & 0.087 \\
\hline Ethyl formate & 8.7 & 8.6 & Malic acid & 1.11 & 1.12 \\
\hline Terbutyl acetate & 4.2 & 4.1 & Lactic acid & 2.75 & 2.78 \\
\hline Isoamyl acetate & 0.98 & 1.02 & Citric acid & 2.2 & 2.2 \\
\hline Caproic acid propyl ester & 1.55 & 1.59 & Succinic acid & 1 & 1.1 \\
\hline Isopentyl hexanoate & 1.6 & 1.36 & Maleic acid & 0.024 & 0.018 \\
\hline Ethyl nonyl & 4.2 & 4.3 & Fumaric acid & 0.18 & 0.2 \\
\hline
\end{tabular}




\section{Continued}

\begin{tabular}{cccccc}
\hline Diethyl butyroacetate & 6.5 & 6.7 & Isoamyl alcohol & 35.4 & 35.2 \\
Phenylethyl acetate & 0.41 & 0.43 & Propyl alcohol & 5.6 & 5.3 \\
methanol & 23.5 & 23.6 & Isovaleraldehyde & 0.9 & 0.8 \\
Isobutanol & 27.1 & 27.2 & Propionic aldehyde & 1.1 & 1.2 \\
N-butanol & 34.2 & 34.2 & Isobutyral & 3.95 & 4.1 \\
SEC butyl alcohol & 3.6 & 3.7 & Furfural & 0.15 & 0.16 \\
Hexanol & 8.9 & 8.7 & N-butyral & 0.11 & 0.13 \\
2,3-butanediol & 1.3 & 1.2 & Acetone & 0.06 & 0.05 \\
Amyl alcohol & 6.3 & 6.2 & Butanone & 0.18 & 0.17 \\
SEC pentyl alcohol & 2.4 & 2.3 & Formaldehyde & 0.99 & 0.98 \\
Acetal & 63.4 & 63.2 & Benzaldehyde & 5.2 & 5.3 \\
Acetaldehyde & 40.1 & 39.7 & & & \\
\hline
\end{tabular}

Table 2. Changes of function factors content in compound pit Luzhou-flavor Liquor of before and after added ocean bacillus.

\begin{tabular}{ccc}
\hline Function factor $(\mu \mathrm{g} / \mathrm{L})$ & Before $(\mu \mathrm{g} / \mathrm{L})$ & After $(\mu \mathrm{g} / \mathrm{L})$ \\
\hline 4-methyl guaiacol & 305.17 & 567.47 \\
4-ethylphenol & 19.64 & 20.05 \\
2,3,4,5,6-Tetramethylpyrazine & 974 & 1400 \\
\hline
\end{tabular}

the addition of marine bacillus BC-2 did not affect the Luzhou-flavor Liquor aroma. Meanwhile, adding the marine bacillus BC-2 can dramatically improve the content of function factor 4-methyl guaiacol and 2,3,4,5,6-Tetramethylpyrazine. Function factor of tetramethylpyrazine can be used for cancer, autoimmune, inflammatory, neuro- and cardiovascular diseases, and is believed to attenuate platelet aggregation, prevent thrombus formation and improve microcirculation as well [12] [13] [14] [15]. Moreover, previous researches proved that function factor 4-methyl guaiacol can against abnormal oxidative stress [16]. It is reasonable to presume that the Luzhou-flavor Liquor produced with the new modified bacillus complex bacterial liquid may have functions of improving microcirculation, anti-tumor and enhancing human immunity and so on.

\section{Conclusion}

Marine bacillus BC-2 is derived from seawater of Mariana Trench and has the characteristics of high-temperature resistance. We add it to pit mud and optimize it. The optimized pit mud used in the production of flavor liquor and it can significantly increase the contents of 4-methyl guaiacol and 2,3,4,5,6-Tetramethylpyrazine in liquor. It demonstrated the marine bacillus BC- 2 with high production value. Liquor produced by optimized pit mud has health function. 


\section{Conflicts of Interest}

The authors declare no conflicts of interest regarding the publication of this paper.

\section{References}

[1] Li, F., Wu, X., Wang, X. and Qiu, S. (2014) Application of Microbiological Technology in Aroma Enhancement of Luzhou-Flavor Liquor. China Brewing, 33, 9-13.

[2] Liang, J., Xiao, Q., Chen, D., Wan, Y. and Zeng, Y. (2015) Study on the Distribution of Trace Elements in Liquors with Brand Based on the Principal Component Analysis. Science and Technology of Food Industry, 36, 67-70.

[3] Wu, T., Yang, H. and Zhang, K. (2002) The Basic Study on Liquor Aroma Related to Chromatograph Skeleton Components in Liquor. Liquor Making, 29, 25-28.

[4] Cheng, L. (2013) A Brief Analysis of the Relation between Several Important Components and Quality of Liquor. Heilongjiang Science and Technology Information, No. 36, 62-63.

[5] Xu, Y., Fan, W., Ge, X. and Huang, Y. (2013) Scientific Recognition of Biofunctional Components in Chinese Liquors. Liquor-Making Science \& Technology, No. 9, $1-6$.

[6] Li, D. (2008) Moderate Drinking Is Helpful for Your Health. Liquor-Making Science \& Technology, No. 10, 133-138.

[7] Wu, J., Huang, M., Sun, B., Zheng, F. and Sun, J. (2014) Analysis of Volatile Compounds in Jingzhi Baigan Liquor by Liquid-Liquid Extraction (LLE) and Gas Chromatography-Mass Spectrometry (GC-MS). Food Science, 35, 72-75.

[8] Fan, H., Fan, W. and Xu, Y. (2015) Characterization of Key Odorants in Chinese Chixiang Aroma-Type Liquor by Gas Chromatography-Olfactometry, Quantitative Measurements, Aroma Recombination, and Omission Studies. Journal of Agricultural and Food Chemistry, 63, 3660-3668. https://doi.org/10.1021/jf506238f

[9] Wu, T., Zhu, S., Sun, X., Zhao, W. and Cui, G. (2013) Analysis of Health Factors of Meilanchun Sesame-Flavor Liquor. Liquor-Making Science \& Technology, No. 8, 125-130.

[10] Ren, J., Yao, W., Tang, Y., Ren, D., Liu, M., Yan, H. and Liu, X.-Y. (2014) Studies on the Cultivate Formula of Hybrid Functional Microorganism of Pit Mud. Liquor Making, 41, 47-50.

[11] Zhang, X., Liu, M., Tang, Y., Zhao, K. and Gu, Y. (2017) Recent Advances in Research on the Community, Isolation, and Application of Microbes in the Pit Mud Used in Manufacture of Chinese Strong-Flavor Baijiu. Microbiology, 44, 1222-1229.

[12] Zhang, M., Gao, F., Teng, F. and Zhang, C. (2014) Tetramethylpyrazine Promotes the Proliferation and Migration of Brain Endothelial Cells. Molecular Medicine Reports, 10, 29-32. https://doi.org/10.3892/mmr.2014.2169

[13] Wu, Y., Xu, Z., Yang, Y., Qiu, J., Yang, M., Wu, C., Lai, Z., Tang, M., Ge, J., Yu, K.M. and Zhuang, J. (2019) Tetramethylpyrazine (TMP) Ameliorates Corneal Neovascularization via Regulating Cell Infiltration into Cornea after Alkali Burn. Biomedicine \& Pharmacotherapy, 109, 1041-1051.

https://doi.org/10.1016/j.biopha.2018.10.091

[14] Shen, J., Zeng, L., Pan, L., Yuan, S., Wu, M. and Kong, X. (2018) Tetramethylpyrazine Regulates Breast Cancer Cell Viability, Migration, Invasion and Apoptosis by Affecting the Activity of Akt and Caspase-3. Oncology Letters, 15, 4557-4563. 
https://doi.org/10.3892/ol.2018.7851

[15] Mehmood, K., Zhang, H., Kashif Iqbal, M., Ur Rehman, M., Li, K., Huang, S.-C., Shahzad, M., Nabi, F., Iqbal, M. and Li, J.-K. (2018) Tetramethylpyrazine Mitigates Toxicity and Liver Oxidative Stress in Tibial Dyschondroplasia Chickens. Pakistan Veterinary Journal, 38, 76-80. https://doi.org/10.29261/pakvetj/2018.015

[16] Zhao, D., Shi, D., Sun, J., Li, H., Zhao, M. and Sun B.-G. (2018) Quantification and Cytoprotection by Vanillin, 4-Methylguaiacol and 4-Ethylguaiacol against AAPHInduced Abnormal Oxidative Stress in HepG2 Cells. RSC Advances, 8, 35474-35484. https://doi.org/10.1039/C8RA06505E 